\title{
Preparation and characterization of PTFE flat sheet membrane: Effect of sodium benzoate content
}

\author{
Faezeah Abd Ghani ${ }^{\text {a, c }}$, Khaidzir Hamzah ${ }^{\text {b, c, }}{ }^{,}$, Wan NorHaryati Wan Salleh ${ }^{\text {a, c }}$, Hasimah \\ Mohamed $^{d}$ \\ a Advanced Membrane Technology Research Centre (AMTEC), Universiti Teknologi Malaysia, 81310 Skudai, Johor Darul Takzim, Malaysia \\ ${ }^{b}$ UTM-MPRC Institute for Oil and Gas, Universiti Teknologi Malaysia, 81310 Skudai, Johor Darul Takzim, Malaysia \\ c Faculty of Chemical and Energy Engineering (FCEE), Universiti Teknologi Malaysia, 81310 Skudai, Johor Darul Takzim, Malaysia \\ d Radiation Processing Technology Division, Malaysian Nuclear Agency, Bangi, 43000 Kajang Selangor, Malaysia \\ * Corresponding author: khaidzir@utm.my
}

Article history

Received 14 February 2017

Accepted 27 October 2017

\begin{abstract}
Polytetrafluoroethylene (PTFE) flat sheet membranes were prepared through casting and sintering methods. The effect of sodium benzoate salt on the characteristics of PTFE flat sheet membranes such as morphology, surface roughness, porosity, mechanical strength and crystallinity were studied through scanning electron microscopy (SEM), atomic force microscopy (AFM), mercury intrusion porosimetry, tensile test and X-ray diffraction (XRD). SEM analysis confirmed the formation of irregular porous microstructures in sponge-like configuration. All the fabricated membranes exhibited narrow pore size distributions and have relatively small average pore diameters between 0.074 and $1.068 \mu \mathrm{m}$ despite having porosity between 36.41 and $74.32 \%$. In addition, surface roughness of the PTFE flat sheet membranes increased as the sodium benzoate content increased. Increasing sodium benzoate content was positive for pore size and porosity but negative for crystallinity and mechanical properties. This research confirmed that the addition of sodium benzoate salt in aqueous PTFE solution is a useful approach for the fabrication of porous PTFE flat sheet membranes.
\end{abstract}

Keywords: Porosity, Polytetrafluoroethylene (PTFE), porous membrane, sodium benzoate, tensile strength

\section{INTRODUCTION}

Polytetrafluoroethylene (PTFE) is a fluorocarbon polymer produced by tetrafluoroethylene polymerization. The strong bonds exist between fluorine and carbon atoms and the specific molecular structure make PTFE has excellent thermostability, chemical inertness, great electrical insulation properties (Fang et al., 2009), low surface energy, low frictional coefficient and low dielectric constant (Wang et al., 2010).

With its unique properties, PTFE has found applications in vanadium redox battery (Qiu et al., 2007), fuel cell (Ramya et al., 2006 and Chen et al., 2005), direct contact membrane distillation desalination (Lai et al., 2011, Taylor et al., 2013 and Zhou et al., 2014), heavy metal removal (Yoo \& Kwak., 2013), oilfield wastewater treatment (Lin et al., 2011) and submergerd membrane bioreactor (Nittami et al., 2012).

In conjunction with various application, more attention has been paid to prepare PTFE membrane. PTFE porous membranes were induced conventionally by extruding and rolling followed by uniaxial and biaxial streching (Kurumadaet al., 1998). Huang et at., (2008) used PID control PTFE paste extrusion system to improve the properties of PTFE paste during extrusion process and pore size. Meanwhile, Zhu et al., (2013) investigated the effect of stretching ratio on the characteristics of PTFE hollow fiber membranes. It was noted that increasing stretching ratio had positive effect for pore size and porosity but negative effect for water entry pressure and mechanical property in membrane distillation application.

Furthermore, Ranjbarzadeh-dibazar et al., (2014) prepared PTFE membranes using thermo-mechanical methods of billet formation, cold extrusion, rolling, uniaxial streching at $100-250{ }^{\circ} \mathrm{C}$ and heat treatment. However, these methods led to poor materials performance stability owing to creeping deformation of PTFE flat sheet membrane. Xiong et al., (2009) fabricated ultrafine fibrous PTFE porous membranes through PVA-assisted PTFE emulsion by electrospinning and sintering. Later, Huang et al., (2013) designed a superhydrophobic microporous PTFE membranes from mixture of PTFE emulsion and PVA aqueous solution by controlling the cooling rate during membrane formation revealed that the micro-nano structures in the membrane were improved. Recently, a super-hydrophobic nanofibrous membrane was prepared by electrospinning and sintering with high water flux for use in membrane distillation Huang et al. (2017). However, all of these methods require work in preparing the PTFE membrane.

Alto et al., (1980) initially proposed a simple method for forming microporous sheet of fluorocarbon polymer especially PTFE by casting and sintering technique. This method consisted of the mixture of PTFE aqueous dispersion, cryztallizable metallic organic salt sodium benzoate as pore forming agent and ethylene glycol as foam 
suppressant. Pore forming agents are often selected from a number of polymer swelling agents which are poor solvents in the polymersolvent interaction spectrum (Ohya et al., 1996). It is believed that higher concentrations of sodium benzoate salts increased the pore size and the pore density of the final products.

Other use of sodium benzoate is mainly focused on preservation of variety of foods, such as marinated fish, fruit based fillings, ham, salad dressings, soft drink and beer (Zhang \& Ma, 2013). Sodium benzoate is the most common food preservative that are listed among the "generally regarded as safe" (GRAS) compounds by the United States Food and Drug Administration (Lennerz et al., 2015). Zubir and Ismail (2003) then studied the effect of sintering temperature on the morphology and mechanical properties of PTFE membrane. However, no comprehensive work dealing with the effect of sodium benzoate on the PTFE flat sheet membrane properties has been reported. Therefore, the objectives of this research is to study the effects of sodium benzoate on the pore size distribution, porosity, roughness, crystallinity, morphology and mechanical strength properties of PTFE flat sheet membranes by casting and sintering techniques.

\section{EXPERIMENTAL}

\section{Materials}

The PTFE polymer in the form of aqueous dispersion (FR301B) was purchased from 3F New Materials Co., Ltd., Shanghai, China. Ethylene glycol (6207) additive was supplied by Merck and acted as a foam suppressant. Sodium benzoate (144.11) salts was provided by Riedel-de-Haen and served as a pore forming agent.

\section{Preparation of PTFE flat sheet membrane by casting and sintering technique}

The PTFE flat sheet membrane was prepared by casting and sintering technique following Alto et al., (1980). Sodium benzoate was dissolved in the mixture of PTFE and ethylene glycol solution at different ratios as summerized in Table 1 . The solutions were stirred vigorously at room temperature $\left(23^{\circ} \mathrm{C} \pm 1^{\circ} \mathrm{C}\right)$ for 3 hours. Then, the obtained casting solution was stored at room temperature for at least 12 hours to remove bubbles. To cast the flat sheet membrane, the solution was spread onto a flat glass plate by using glass rod. The glass plate was taped side by side to control the thickness of the PTFE flat sheet membrane. The exposed surface of the wet casted PTFE flat sheet membrane was left air-dried at room temperature. The dried PTFE flat sheet membrane was sintered in a furnace for 30 minutes at $385^{\circ} \mathrm{C}$. The sintered PTFE flat sheet membrane was permitted to cool to room temperature. The PTFE flat sheet membrane was leached by immersing the membrane into a hot water bath at $70{ }^{\circ} \mathrm{C}$ for 2 hours to detach the membrane from the glass plate. Finally, the resulting PTFE flat sheet membrane was then removed and being air-dried at room temperature.

\section{Characterization of PTFE flat sheet membrane}

Pore size distributions of the PTFE flat sheet membranes were determined by mercury intrusion porosimeter Autopore V, Micromeritics Instrument Corp. (USA). The values of surface tension and contact angle used in the computational program of the porosimeter were $0.485 \mathrm{~N} / \mathrm{m}$ and $130^{\circ}$, respectively. Morphologhy surface and fractured surface of the PTFE flat sheet membranes were studied using a scanning electron microscope JEOL JSM6390LV(Japan). Surface roughness of the PTFE flat sheet membranes were analysed at room temperature by atomic force microscopy (AFM) JPK NanoWizard II (Germany). Crystalline structures of the synthesized PTFE flat sheet membranes were analyzed by X-ray diffractometer (XRD) Panalytical X'Pert Pro MRD (Netherlands) equipped with a $\mathrm{Cu} \mathrm{K} \alpha$ radiation source $(40 \mathrm{kV}, 30 \mathrm{~mA})$. The samples were scanned in the range of diffraction angle $2 \theta$ from $5^{\circ}$ to $90^{\circ}$. Tensile strength tests were performed by LRX $2.5 \mathrm{KN}$ Lloyd Tensile Tester (UK). The samples were cut into dumbell-shaped following ASTM D882. The tests were performed at room temperature with a crosshead speed of $50 \mathrm{~mm} / \mathrm{min}$. A minimums of five specimens were tested for each sample.
Table 1 Dope formulations for PTFE flat sheet membrane casting solution.

Samples $\quad$ PTFE (g) $\begin{gathered}\text { Sodium } \\ \text { benzoate (g) }\end{gathered} \quad \begin{gathered}\text { Ethylene } \\ \text { glycol }(g)\end{gathered}$

$\begin{array}{llll}\text { PTFE1 } & 100 & 10 & 10 \\ \text { PTFE2 } & 100 & 15 & 10 \\ \text { PTFE3 } & 100 & 25 & 10\end{array}$

\section{RESULTS AND DISCUSSION}

\section{The pore size distributions of PTFE flat sheet membranes as a function of sodium benzoate}

Table 2 shows the pore size distributions of the PTFE flat sheet membranes. The porosity of the PTFE flat sheet membrane is in the range of $36.41 \%$ to $74.32 \%$ meanwhile the average pore diameter of PTFE flat sheet membranes is in the range of $74.8 \mathrm{~nm}$ to $1068.4 \mathrm{~nm}$. A similar trend was reported by Ranjbarzadeh et al. (2014) who used stretching technique in their work. It can be clearly seen that the average pore diameter and porosity of the PTFE flat sheet membranes increased with the increased of sodium benzoate. This results proved the function of sodium benzote as pore forming agent. As reported by Bakhtiari et al.(2015), pore forming agent molecules usually move into the hydrophobic core of micelle structure and expands them, thereby increasing the pore size of the materials.

Table 2 Physical characteristics of PTFE flat sheet membrane.

\begin{tabular}{ccccccc}
\hline \multirow{2}{*}{ Sample } & \multicolumn{2}{c}{$\begin{array}{c}\text { Pore size } \\
\text { distribution }\end{array}$} & & \multicolumn{3}{c}{ Roughness parameter } \\
\cline { 2 - 3 } & $\begin{array}{c}\text { Poro } \\
\text { sity } \\
(\%)\end{array}$ & $\begin{array}{c}\text { Avg } \\
\text { pore } \mathbf{D} \\
(\mathbf{n m})\end{array}$ & $\begin{array}{c}\text { Peak-to- } \\
\text { valley } \\
\text { roughne } \\
\mathbf{s}, \mathbf{R}_{\mathbf{t}} \\
(\mathbf{n m})\end{array}$ & $\begin{array}{c}\text { Avg } \\
\text { roughn } \\
\text { ess, } \mathbf{R}_{\mathbf{a}} \\
(\mathbf{n m})\end{array}$ & $\begin{array}{c}\text { RMS } \\
\text { roughness, } \\
\mathbf{R}_{\mathbf{q}}(\mathbf{n m})\end{array}$ \\
\hline PTFE1 & 36.41 & 74.8 & 738.8 & 102.2 & 125.5 \\
PTFE2 & 50.51 & 164.7 & 1063 & 112.1 & 145.2 \\
PTFE3 & 74.32 & 1068.4 & 1814 & 196.9 & 255.2 \\
\hline
\end{tabular}

\section{The morphology of PTFE flat sheet membrane as a function on sodium benzoate}

Fig. 1 presents the surface and fractured surface of the PTFE flat sheet membranes which is the one that formed by exposure to the surrounding environment during drying and sintering processes. It is shown that the membrane pores increased obviously with the increased in sodium benzote content. It is apparent in Figure 1(a-c), that the pores are interconnected within the bulk of the membrane are interlaced and intertwined into the void network of intersecting shafts forming a matte and a porous surface on the PTFE flat sheet membrane. The lighter colour comprises the solid portion of membrane, while the darker comprises the pores or voids.

It is observed that PTFE1 has smoother surface compared to PTFE2 and PTFE3 due to less sodium benzoate content that resulted to less pore formation. The fractured surfaces illustrated in Figure 1(d)-(f) shows that the irregular porous structure in a fingerlike configuration can only be seen in PTFE2 and PTFE3. It is assumed that the void space network on the top surface continues downwardly into the membrane forming intertwined pore paths. In addition, the pore structure was obviously different from the node-fibril structures that typically obtained by stretching method for PTFE flat sheet membrane preparation. A similar structures was reported Huang et al (2013) who fabricated PTFE membranes from a mixture of PTFE emulsion and PVA aqueous solution. 

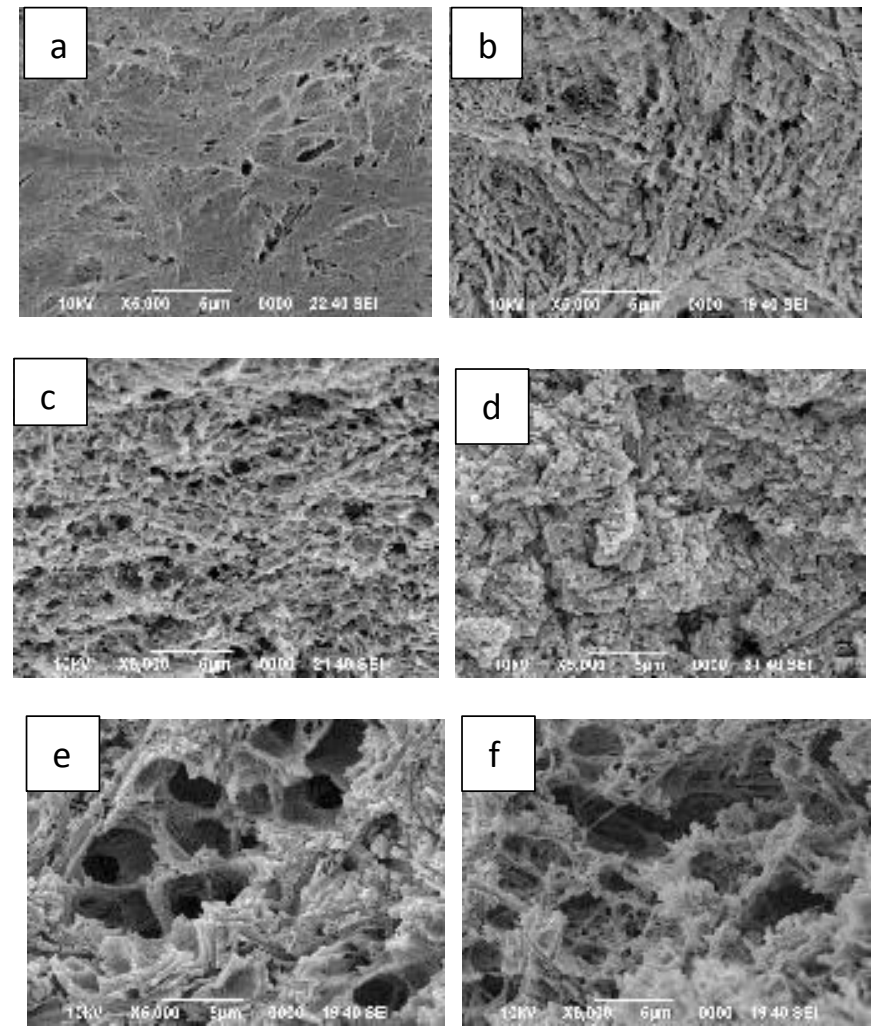

Figure 1 SEM images of PTFE flat sheet membrane surfaces; a) PTFE1; b) PTFE2; c) PTFE3 and fractured surfaces; d) PTFE1; e) PTFE2; f) PTFE3.

\section{The roughness of PTFE flat sheet membrane as a function of sodium benzoate}

Fig. 2(a)-(c) are the 2D and 3D vertical profile of AFM images of the PTFE flat sheet membranes over an area of $5.0 \times 5.0 \mu \mathrm{m}$. The light regions is the highest points and the darkest regions is the pores. It can be observed that PTFE3 has big well-defined dark areas compared to PTFE1 and PTFE2. The result is consistent with the SEM observation. Surface roughness characteristics such as peak-tovalley roughness $\left(R_{t}\right)$, average roughness $\left(R_{a}\right)$ and root mean square (RMS) roughness $\left(\mathrm{R}_{\mathrm{q}}\right)$ are summarized in Table 2. It is apparent, that the surface roughness characteristics of the PTFE flat sheet membrane increases systematically with increasing sodium benzoate content. PTFE1 was relatively smooth with RMS roughness of $125.5 \mathrm{~nm}$. PTFE2 showed slightly higher in RMS roughness of $145.2 \mathrm{~nm}$ and increased to $255.2 \mathrm{~nm}$ for PTFE3 membrane. The increase in RMS roughness could be due to the increased of pore size. This result is in agreement with Bowen et al. (1999) on their studies on ultrafiltration membranes with different molecular weight cut off.

\section{The crystallinity of PTFE flat sheet membrane as a function of sodium benzoate}

Fig. 4 indicates an XRD patterns of the PTFE flat sheet membranes. A sharp peak around $2 \theta=17.90^{\circ}$ appeared in all samples corresponds to the crystallization peak of the pure PTFE semicrystalline. For PTFE1, the X-ray can easily penetrate the membrane and detect the pure PTFE semicrystalline. However, for the PTFE2 and PTFE3, its intensity weakened due to the increased of sodium benzoate. It is possible that the fluorine was extracted and broke the symmetric structure of PTFE flat sheet membrane by the sodium benzoate. Thus, the crystallinity decreased accordingly. The result is in agreement with previous work done by Wang et al. (2010) on modified PTFE surface by chemical oxidation.

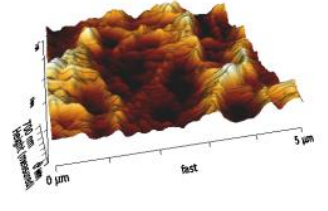

(a)
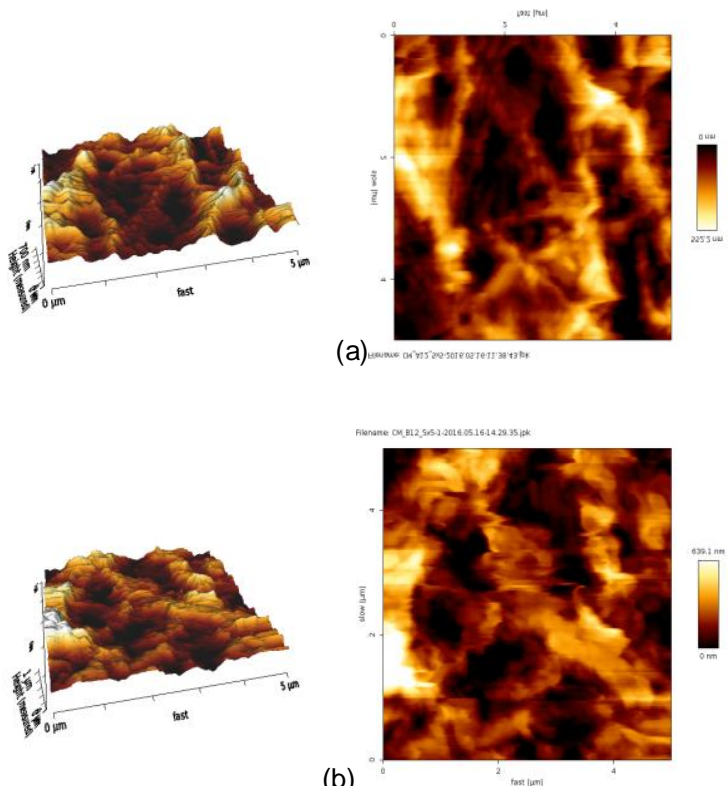

(b)
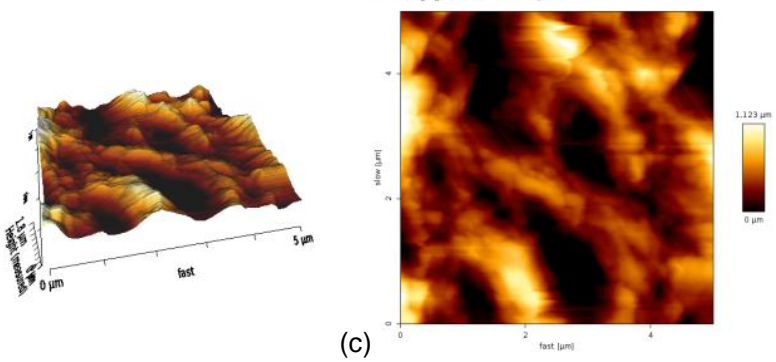

Figure 2 3D and 2D image profiles of a) PTFE1, b) PTFE2 and c) PTFE3.

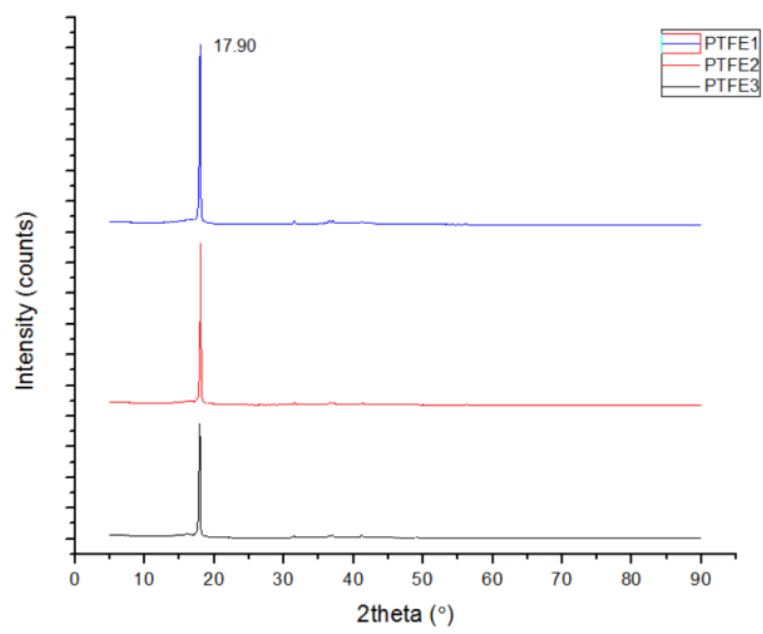

Figure 4 XRD patterns for PTFE1, PTFE2 and PTFE3.

\section{The mechanical strength of PTFE flat sheet membrane as a} function of sodium benzoate

Table 3 presents the tensile strength, tensile strain, Young's modulus and elongation at break of the PTFE flat sheet membranes. As sodium benzoate increased, the tensile strength decreases slightly from 0.31 MPa to $0.16 \mathrm{MPa}$. Similar trend can be seen on the elongation at break and the tensile strain. The elongation at break for PTFE1 was $130.74 \mathrm{~mm}$ and $85.84 \mathrm{~mm}$ for PTFE3. The value of tensile strain was $344.04 \%$ for PTFE1 and $225.90 \%$ for PTFE3. Hence, PTFE1 would be more favourable as it has higher tensile 
strength and tensile strain. The Young's modulus was shown in order to determine the alterations made on the stiffness of membrane due to the content of sodium benzoate. Results found that the PTFE1 has the highest Young's modulus of $1397.00 \mathrm{MPa}$ as compared to the PTFE2 and PTFE3. Overall, tensile studies showed that the PTFE1 has generate higher mechanical strength compared to PTFE2 and PTFE3. The lowest value in mechanical strength for the PTFE3 was most likely due to large pores size as shown in SEM. This result is in agreement with previous work done by Khadijah et al. (2016) on the effect of kaolin content and non-solvent coagulant bath on low cost porous ceramic membrane.

Table 3 Tensile properties of PTFE flat sheet membrane.

\begin{tabular}{ccccc}
\hline Samples & $\begin{array}{c}\text { Tensile } \\
\text { Strength } \\
(\mathbf{M P a})\end{array}$ & $\begin{array}{c}\text { Tensile } \\
\text { Strain } \\
(\%)\end{array}$ & $\begin{array}{c}\text { Young's } \\
\text { modulus } \\
(\mathbf{M P a})\end{array}$ & $\begin{array}{c}\text { Elongation } \\
\text { at break } \\
(\mathbf{m m})\end{array}$ \\
\hline PTFE1 & 0.31 & 344.04 & 1397.00 & 130.74 \\
PTFE2 & 0.26 & 272.43 & 294.68 & 103.52 \\
PTFE3 & 0.16 & 225.90 & 660.95 & 85.84 \\
\hline
\end{tabular}

\section{CONCLUSION}

PTFE flat sheet membranes were prepared by casting and sintering technique. In this research, the influences of sodium benzote on the pore size distribution, porosity, morphology, surface roughness, crystallinity and mechanical strength were studied. The results shows that the content of sodium benzoate strongly affect the properties of PTFE flat sheet membrane. At higher sodium benzoate content, the resultant membrane showed better pore sponge-like configuration with higher average pore diameter and porosity. The surface roughness also increased as the content of sodium benzoate increased. Nevertheless, crystallinity and mechanical strength has decreased as sodium benzate content increased. These results may broaden the application of the PTFE flat sheet membrane especially as adsorbent and other applications in future.

\section{ACKNOWLEDGMENTS}

The authors gratefully acknowledged the financial support from Ministry of Higher Education and Universiti Teknologi Malaysia (UTM) under MyBrain Fellowship and Fundamental Research Grant Scheme, FRGS (R.J130000.7826.4F752). The authors would also like to acknowledge technical and management support from Radiation Processing Technology Division, Malaysian Nuclear Agency and Research Management Centre (RMC), Universiti Teknologi Malaysia.

\section{REFERENCES}

Alto, P., Mark, C. and Anderson, P. E. (1980). United States Patent No. 4,196,070. Pleasanton California: Nuclepore Corporation.

Bakhtiari, L., Javadpour, J., Rezaie, H. R., Erfan, M. and Shokrgozar, M. A. 2015. The effect of swelling agent on the pore characteristics of mesoporous hydroxyapatite nanoparticles. Progress in Natural Science: Materials International, 25(3), 185-190.

Bowen, W. R., Hilal, H., Lovitt, R. W. and Wright, C. J. 1999. Atomic Force Microscope Studies of Membrane Surfaces. In: Sorensen T. S. (Ed.) Surface chemistry and electrochemistry of membranes. Surfactant Science Series, Vol 79 (p1). New York: Dekker.
Fang, Z., Hao, L., Yang, H., Xie, X., Qiu, Y. and Edmund, K. 2009. Polytetrafluoroethylene surface modification by filamentary and homogeneous dielectric barrier discharges in air. Applied Surface Science, 255(16), 7279-7285.

Huang, L., Hsu, P. and Kuo, C. 2008. Pore size control of PTFE membranes by stretch operation with asymmetric heating system. Desalination, 233(1-3), 64-72.

Huang, Y., Huang, Q., Liu, H., Zhang, C., You, Y., Li, N. and Xiao, C. 2017. Journal of Membrane Science, 523(399), 317-326.

Huang, Q., Xiao, C., Feng, X. and Hu, X. 2013. Design of super-hydrophobic microporous polytetrafluoroethylene membrane. New Journal Chemistry, 373-379.

Khadijah, S. and Harun, Z. 2016. Chemical Engineering research and design preparation and characterization of low cost porous ceramic membrane support from kaolin using phase inversion/sintering technique for gas separation: Effect of kaolin content and non-solvent coagulant bath. Chemical Engineering Research and Design, 112, 24-35.

Kurumada, K., Kitamura, T., Fukumoto, N. and Oshima, M. 1998. Structure generation in PTFE porous membranes induced by the uniaxial and biaxial stretching operations, Journal of Membrane Science, 149, 51-57.

Lai, C., Liou, R., Chen, S., Huang, G., \& Lee, K. 2011. Preparation and characterization of plasma-modified PTFE membrane and its application in direct contact membrane distillation. Desalination, 267(2-3), 184-192.

Lennerz, B. S., Vafai, S. B., Delaney, N. F., Clish, C. B., Deik, A. A., Pierce, K. A., Mootha, V. K. 2015. Effects of sodium benzoate, a widely used food preservative, on glucose homeostasis and metabolic profiles in humans. Molecular Genetics and Metabolism, 114(1), 73-79.

Lin, A., Shao, S., Li, H., Yang, D., Kong, Y. 2011. Preparation and characterization of a new negatively charged polytetrafluoroethylene membrane for treating oilfield wastewater. Journal of Membrane Science, 371(1-2), 286-292.

Nittami, T., Hitomi, T., Matsumoto, K., Nakamura, K., Ikeda, T., Setoguchi, Y., Motoori, M. 2012. Comparison of Polytetrafluoroethylene flat-sheet membranes with different pore sizes in application to submerged Membrane Bioreactor, 228-236.

Ohya, H., Kudryavtsev, V.V., Semenova, S.I. 1996. Polyimide Membranes: Application, Fabrications and Properties ( $1^{\text {st }}$ ed.) Tokyo.: Kodansha Ltd.

Qiu, J., Ni, J., Ã, M. Z., Peng, J., Zhou, H., Li, J., Wei, G. 200). Radiation grafting of styrene and maleic anhydride onto PTFE membranes and sequent sulfonation for applications of vanadium redox battery, Radiation Physics and Chemistry, 76, 1703-1707.

Ramya, K., Velayutham, G., Subramaniam, C. K., Rajalakshmi, N., Dhathathreyan, K. S. 2006. Effect of solvents on the characteristics of Nafion ® / PTFE composite membranes for fuel cell applications, Journal of Power Sources, 160, 10-17.

Ranjbarzadeh-dibazar, A., Shokrollahi, P., Barzin, J., Rahimi, A. 2014. Lubricant facilitated thermo-mechanical stretching of PTFE and morphology of the resulting membranes. Journal of Membrane Science, 470, 458-469.

Wang, S., Li, J., Suo, J., Luo, T. 2010. Surface modification of porous poly(tetrafluoraethylene) film by a simple chemical oxidation treatment. Applied Surface Science, 256(7), 2293-2298.

Xiong, J., Huo, P., Ko, F. K., Introduction, I. 2009. Fabrication of ultrafine fibrous polytetrafluoroethylene porous membranes by electrospinning. Journal Materials Research Society, 2755-2761.

Yoo, H., Kwak, S. 2013. Surface functionalization of PTFE membranes with hyperbranched poly (amidoamine) for the removal of $\mathrm{Cu} 2+$ ions from aqueous solution. Journal of Membrane Science, 448, 125-134.

Zhang, G., Ma, Y. 2013. Spectroscopic studies on the interaction of sodium benzoate , a food preservative, with calf thymus DNA. Food Chemistry, 141(1), 41-47.

Zhu, H., Wang, H., Wang, F., Guo, Y., Zhang, H. 2013. Preparation and properties of PTFE hollow fi ber membranes for desalination through vacuum membrane distillation. Journal of Membrane Science, 446, 145 153.

Zubir, N. A., Ismail, A. F. 2002. Effect of sintering temperature on the morphology and mechanical properties of PTFE membranes as a base substrate for proton exchange membrane. Songklanakarin Journal Science Technology, 823-831. 